\title{
A Wolfrom transmission without carrier
}

\author{
B.-R. Höhn, $Y$. Zhang, M. Geitner, and $M$. Otto
}

\begin{abstract}
Wolfrom-transmission are well known planetary transmission with low number of gears and used for very high transmission - ratio for example : $\mathrm{i}=100$ or more. With the book of Mueller "Die Umlaufgetriebe" they are a type of reduced planetary transmission containing two simple transmission one a minus-type and one a plus-type for the two transmission inside. With a common carrier for both transmission and only one sun and two inner gears it is very compact but known for bad efficiency. Firms who produces such transmission are talking about a lot of problems, but no details are published so long. The Author will show that a calculation with low-loss-gears will improve the efficiency very much and that we can produce this type without a carrier. The forces which are active at the planet should be go direct to the housing and not about bearings in a carrier. Details and a modelling of such type will be presented in the conference.
\end{abstract}

\section{Introduction}

Wolfrom-transmissions are well-known by all gear and transmission designers. A very high gear ratio in a compact design by a reduced planetary transmission with one carrier and only 5 (in some cases only 4) different gears is one of the main advantages of this applications. The disadvantages of such a transmission are represented by high costs as two different ring gears are used and a low efficiency due to high power in the gear mesh of the ring gears (so-called "blind power"). The power in the gear mesh of both ring gears is much higher than the input power at the sun of the Wolfrom transmission [1], [2], [3]. Furthermore, the inconsistency in the measured efficiency is disadvantageous. All companies that produce such transmission systems try to manufacture all parts with low tolerances- often with unsatisfactory results. So far, these transmission systems are only rarely produced and used in practical applications as the range of efficiency is too expanded. Details on the design and the properties of developed systems are usually not published as no one wants to acknowledge the problems.

Against this background, two goals can be specified:

1. Reduction of the losses in gear mesh of the internal gears to achieve smaller heating energy than for existing gear meshes.

2.Design without carrier: The Wolfrom transmission can be built without a planet carrier as no torque moments are transmitted by the carrier. Consequently, all losses resulting from the carrier or any supporting bearings in the carrier or bearings centering the carrier in the housing are zero, since, non-existing bearings have also no losses. Of course, some contact areas to support the planets will be present between the remaining parts.

These two challenges will be shown in this presentation. First of all, the state of the art for Wolfrom transmissions without carrier will be shown in Chapter 2 .
This topic is more or less comprehensively treated in patents or patent applications. In Chapter 3, the use of low loss gears for especially the mesh of ring gear and planet gear will be presented.

\section{Wolfrom transmission without carriers}

Many patents and patent applications in literature exist. Following, only three are to be discussed and illustrated within pictures. The first application is the DE 4224850 A1 from the year 1984 [5]. In Fig.1, the twisting moment of the two ring gears is shown. The mesh forces are in opposite direction and the twisting moment will typically twist the carrier and lead to necessary modifications in the gear meshes of the two internal gears with the one planet gear (like here in this patent application). These modifications are calculated for one torque.

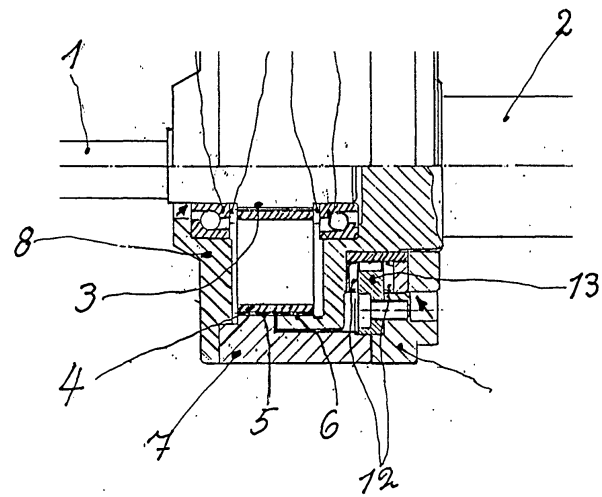

Fig. 1. Wolfrom transmission DE 4224850 A1 [5].

This means that the twisting moment leads to a deformation of the carrier. In this design without carrier the twisting moment will be supported by the gear mesh planet-sun. The tooth width of the sun gear here is larger than necessary for the transmitted torque moment.

Corresponding author: hoehn@,fzg.mw.tum.de 
Nevertheless, there is no carrier and the twisting moment has to be supported by the gear mesh planet-sun. The author doesn't declare whether this application is built or not. The claims of this patent application are formulated in German. The main specification is that the planet (4) is an elastic ring. Though, the planets are fixed without gaps between ring gear and sun. The efficiency must be worse! $[5]$ :

Following, the first claim is quoted (in German)

1. Wolfrom-Planetengetriebe, bei dem ein angetriebenes Sonnenrad in mindestens zwei um das Sonnenrad kreisenden in einem feststehenden ersten Hohlrad steglos geführten axial durchgehend stufenlos verzahnten Planetenrädern kämmt, die wiederum gleichzeitig in ein koaxial zu dem feststehen- den ersten Hohlrad an-geordnetes drehbares zweites mit der Getriebeabtriebswelle fest verbundenes Hohlrad mit einer gegenüber dem ersten Hohlrad geringfügig unterschiedlichen Zähnezahl eingreifen, dadurch gekennzeichnet, dass die Verzahnung eine Schrägverzahnung mit einem Modul von kleiner als 1 und einer Überdeckung von mindestens 4 ist, bei der die jeweils etwa gleiche Zahnbreite des ersten und zweiten Hohlrades $(5,6)$ mindestens dem etwa 35 fachen Wert des gewählten Moduls entspricht, und dass die Planetenräder (4) außenverzahnte gegenüber den Gegenzahnrädern (3, 5, 6) radial elastisch verspannt eingebaute Hohlzylinder sind, deren Breite in etwa der summierten Breite des ersten und zweiten Hohlrades (5, 6) entspricht.

The second patent is DE $202009018547 \mathrm{U} 1$ [6] from 2009. Fig. 2 shows that the Wolfrom transmission is valid for a different number of teeth of the two internal gears. In the patent, it is referred to the twisting moment out of the two internal gears, which should be applied to the sliding parts 33 (not shown) and 34. The efficiency of these sliding parts is low, which results in a not acceptable overall efficiency. But the planet $(40-$ not shown) can be fixed on part 43 (not shown) and can give the radial forces out of the gear mesh ring gear - planet with sliding (!!) to the part 43 .

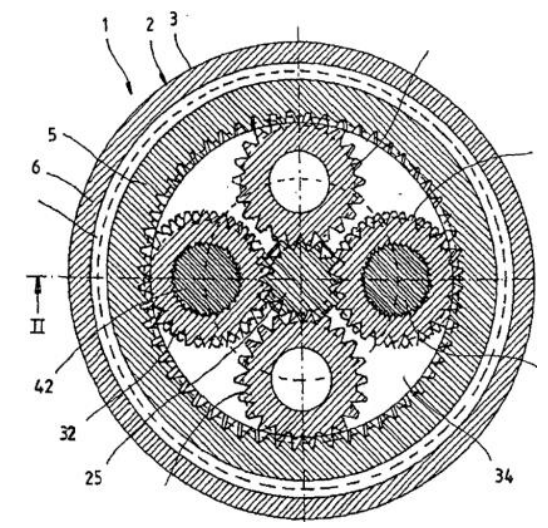

Fig. 2. Wolfrom transmission DE 202009 018547U1 [6]

Following, the first claim is quoted (in German):

1. Wolfrom'sches, stegloses Umlaufrädergetriebe (1), umfassend zwei zueinander koaxiale, gegeneinander verdrehbare Gehäuseteile (5, 14; 6, 15) mit je einer Innenverzahnung $(29 ; 30)$ an der betreffenden Innenseite, ein verzahntes Sonnenrad (25) so wie mehrere verzahnte Planetenräder $(31,32)$, welche zwischen dem Sonnenrad (25) und den lnnenverzahnungen (29; 30) abrollen und fliegend gelagert sind, $d$. h. ohne einen Planetenradträger, sondern in dem ihre Stirnseiten $(38,39)$ zwischen zwei ebenen, zueinander parallelen, ringförmigen Gleitflächen entlanggleiten, welche an den Innenseiten der Stirnflächen $(14 ; 16)$ der beiden Gehäuseteile (5, 14; $6,15)$ angeordnet sind, gekennzeichnet durch eine Wälzlagerung (4) zwischen den beiden Gehäuseteilen (5, 14; 6, 15), deren Wälzkörper (8) auf Bahnen umlaufen, welche sich a) radial außerhalb wenigstens einer Innenverzahnung $(29,30)$ befinden, sowie b) auf einer axialen Höhe zwischen den beiden Gleitflächen des Gehäuses (2; 5, 14; 6, 15) zur Führung der Planetenräder $(31,32)$.

The third example is DE 19845 182A1 [7] from 2000. Fig. 3 and Fig. 4 show the main design. The parts 12 and 4 represent the supporting sun gears (in German: "Stützsonne"). An unsolved challenge of this application is that the twisting moment out of the tangential forces of the internal gears can only be applied to the sliding parts, which can be identified in Fig. 3. This is unlikely possible (authors meaning). Wolfrom transmissions can be designed with just one planet (Fig. 4) or with two different gears as a stepped planet (see Fig. 3). The radial forces out of the gear mesh of the two internal gears with the plan-ets should load the axial elements, especially the shown sliding elements (see Fig. 3).

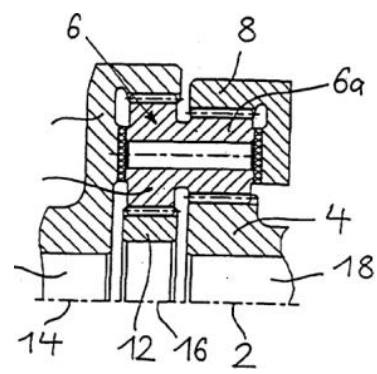

Fig. 3. DE 19845 182A1 [7].

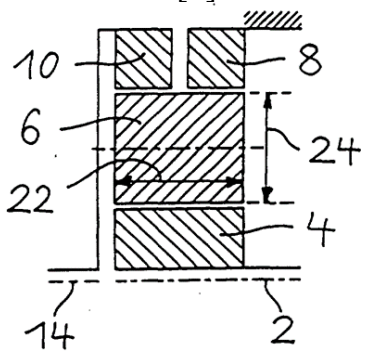

Fig. 4. DE 19845 182A1 [7]. $[7]$ :

Following, the first claim is quoted (in German)

1. Zweistufiges, stegloses Planetengetriebe in Wolfromanordnung, bestehend aus: einem als Antriebsrad (4) dienenden Sonnenrad (Ritzel), das mit der Antriebsachse (2) der Motorwelle (18) verbunden ist, einem mit einer Antriebswelle (20) verbundenen, als Abtriebsrad (10) dienenden Hohlrad, einem Festrad 
(8), das als weiteres Hohlrad dem Antriebshohlrad (4) gegenübersteht, und mindestens einem Planetenrad (6), das einerseits zwischen Fest- (8) und Antriebsrad (4) in Eingriff stehend angeordnet ist und andererseits mit dem Abtriebshohlrad (10) in Wirk-verbindung steht, dadurch gekennzeichnet, daß das Planetenrad (bzw. die Planetenräder) (6) als Stufenplanet(en) (6a, 6b) ausgebildet ist (sind), wobei die dem Abtriebsrad (10) zugeordnete Stufe (6a) von einem Hilfsrad ("Stützsonne" 12) abgestützt wird, und wobei die Drehachse (16) fluchtend zur Antriebs/ Abtriebsachse (2/14) verläuft.

Nevertheless, this patent application is close to the application within this paper, which is shown in Chapter 4. However, this design shows high sliding forces at the flanks of the additional supporting sun ("Stützsonne"). Here, both flanks are loaded and generate losses and heating. Though, the efficiency cannot be increased compared to existing Wolfrom transmissions.

\section{Wolfrom transmission with low-loss- gear}

The Wolfrom transmission is a reduced planetary gear, which can be analysed according to Müller [1]. Fig. 5 shows the schematic design of such a reduced planetary gear with two sub-transmissions and only one common carrier.

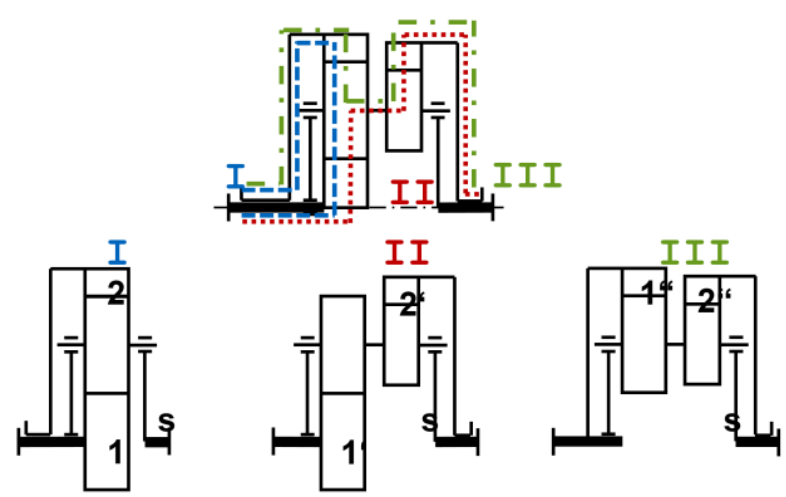

Fig. 5. Analysis of Wolfrom-transmission, 3 possible planetary transmission [1].

The sun 1 and 1 ' could be one part. The 3 subtransmission are a normal "minus-transmission" which is shown as transmission I. The 2 nd sub-transmission is a "minus-transmission" with a stepped planet, which is seen as transmission II and the 3rd sub-transmission is a plus-transmission with two ring gears, which is shown as transmission III.

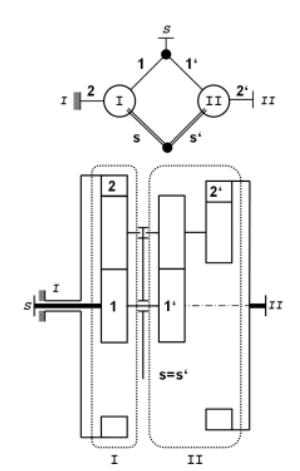

a)
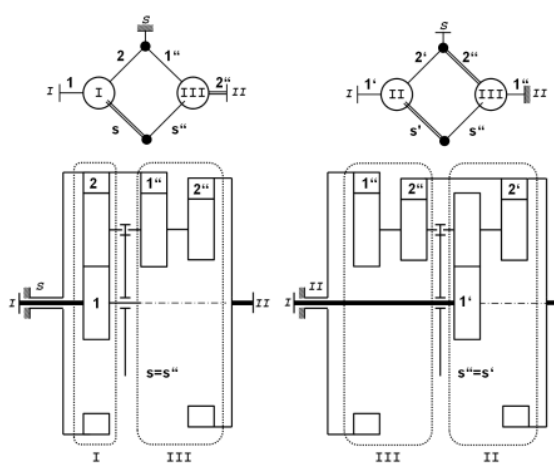

b) Functionally-Equivalent

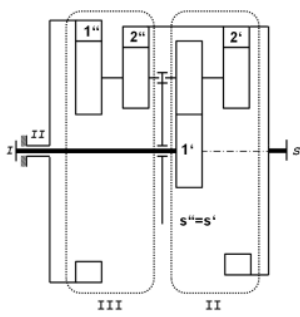

c)
Fig.6. Wolf symbols for kinematically equivalent substitution [1], p.191.

Fig. 6 shows the Wolfsymbols of all possibilities. All possibilities are kinematically equivalent but only one is functionally equivalent. That means this variant has the same efficiency than the existing Wolfrom transmissions.
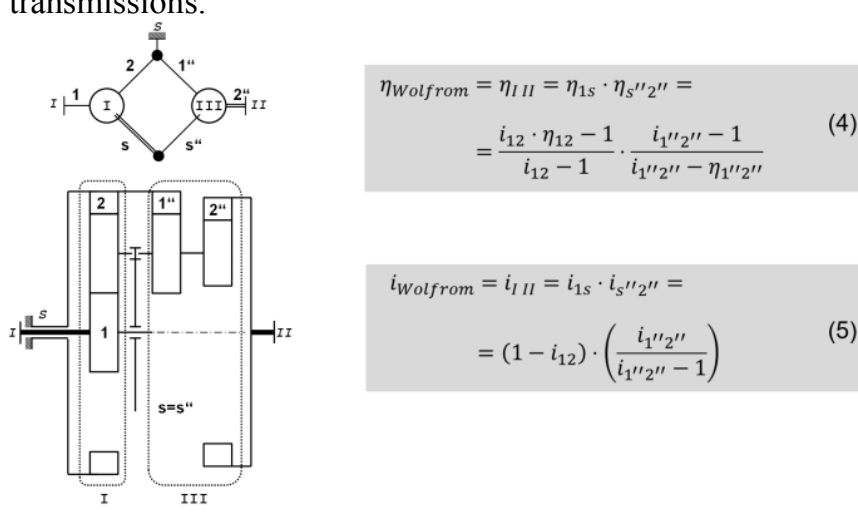

Fig. 7. Efficiency and ratio for Wolfrom transmission [1]

Fig. 7 shows the calculation equations of the efficiency (4) and the transmission ratio (5) for this functionally equivalent configuration of the Wolfrom transmission. It can be seen that the efficiency for the plus-transmission III will become low as the "blindpower" as well as the losses in the gear mesh are very high compared to the losses in sub-transmission I. The special characteristic of this plus-transmission is that the two planets have the same number of teeth. This means that both planets are the same part with only one gear geometry. This Wolfrom transmission has a low transmission ratio as the number of teeth of both ring gears has the difference of the number of planets (see equation 5.11 in [1], p. 237). The transmission ratio is close to $i=$ 1. Fig. 8 and Fig. 9 show the example of such a Wolfrom transmission with a pre-dimensioning acc. to Niemann/Winter [4] with the ZG program plan-gear. The result is remarkable. If you dimension the two subtransmissions separately, which is shown in Fig. 8, you can see that the sub- transmission I can be designed much smaller than it is usual. Wolfrom transmissions are dimensioned with the two internal gears. This means that the module is calculated for the gear meshes of planet to the two internal gears, which here is sub-transmission III. This module is typically also used for the subtransmission I. A separate calculation of subtransmission I (see Fig. 9) shows that this transmission 
can be made with a much smaller module, the size is only $\mathrm{d}_{2}=600 \mathrm{~mm}$ for this example, the diameter for subtransmission III is about $\mathrm{d}=1500 \mathrm{~mm}$. The disadvantage is that you have more different parts, but with only one carrier (but more complex). Therefore, gear engineers would rarely choose this concept for a wide range of practical applications. Only for this special purpose, such as for example an adjustable wind turbine transmission, this concept could be of relevance.

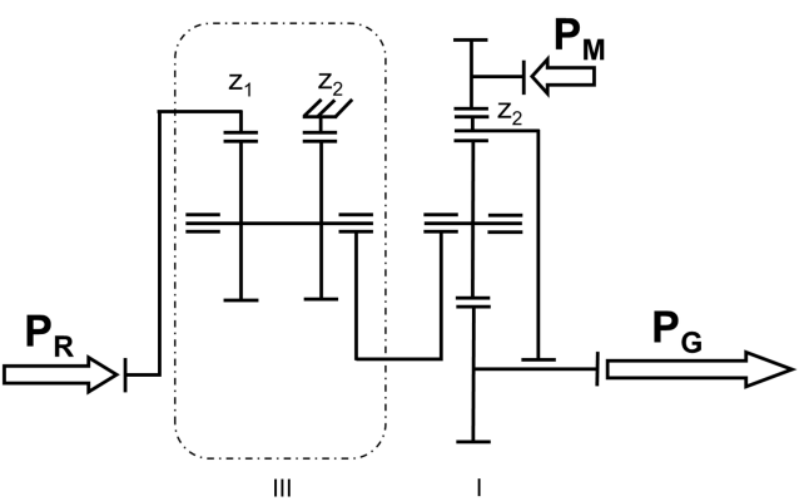

Fig.8. Functionally equivalent Wolfrom transmission for $\mathrm{i} \approx 100$

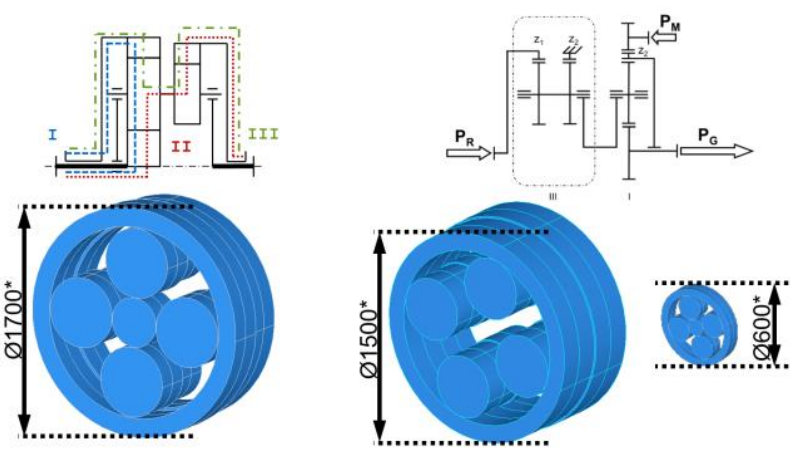

Fig.9. Pre-dimensioning acc. to [4] with ZG program plan-gear.

The challenge is the calculation of module and the gear meshes with low-loss-gears in comparison to a normal design with $\varepsilon_{\alpha} \approx 1.7$. Low-loss-gears have typical values of $\varepsilon_{\alpha} \approx 1.1$ for reduction of sliding and lower values for HV [8]. The advantage of low-loss-gears takes effect if the pitch point $\mathrm{C}$ is in the middle of the line of contact within the beginning of contact (point $\mathrm{A}$ and the end of contact (point E).

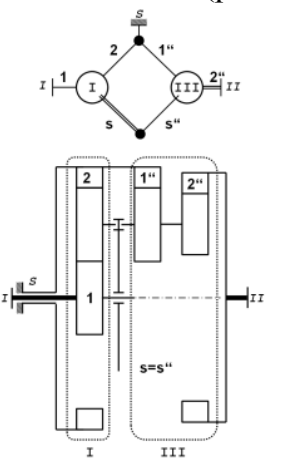

\begin{tabular}{|l|l|c|c|}
\hline Design Results Sub-Transmission I \\
\hline Basic transmission ratio & $i_{12}$ & \multicolumn{2}{|c|}{-3.8} \\
\hline Number of planets & $\mathrm{n}_{\mathrm{pl}}$ & \multicolumn{2}{|c|}{4} \\
\hline Gearing & $\mathrm{x}: \mathrm{y}$ & $1: \mathrm{p}$ & $2: \mathrm{p}$ \\
\hline Number of teeth & $\mathrm{z}_{\mathrm{x}}: \mathrm{z}_{\mathrm{y}}$ & $20: 29$ & $-76: 29$ \\
\hline Mean coeff. of friction & $\mu_{\mathrm{m}, \mathrm{xy}}$ & 0.0443 & 0.0141 \\
\hline Tooth loss factor & $\mathrm{H}_{\mathrm{V}, \mathrm{y}}$ & 0.1414 & 0.0338 \\
\hline Gearing efficiency & $\eta_{\mathrm{xy}}$ & 0.9937 & 0.9995 \\
\hline Basic transmission efficiency & $\eta_{12}$ & \multicolumn{4}{|c|}{0.9932} \\
\hline
\end{tabular}

Fig. 10. low-loss-gears for sub-transmission I.

Fig. 10 shows the result for sub-transmission I, the minus-transmission. The pro-gram calculates the values for $\eta$ with the given parameters of the gear mesh. These values are different for every configuration and not valid for all applications. It can be seen that the friction coefficient is low for the gear mesh internal gear - planet and especially the geometric sliding factor $\mathrm{HV}$ is less than $25 \%$ of the value for the gear mesh sun-planet. The result is that the gearing efficiency for the gear mesh sun-planet is about 0.994 and for the internal gear-planet even 0.9995. That means the losses in the mesh internal gear-planet are only roughly $10 \%$ of those in the mesh sun-planet. For losses so low in the gear mesh concave convex in comparison to the gear mesh convex - convex, the existing "blind power" has not a significant influence on the losses in a Wolfrom transmission.
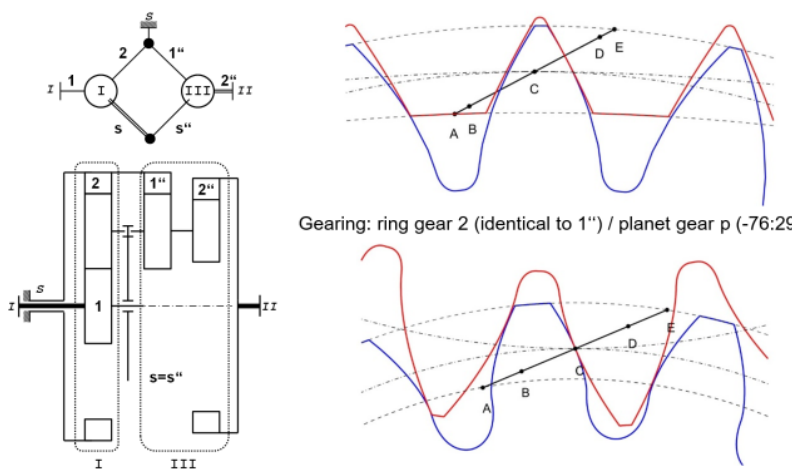

Gearing: ring gear 2 (identical to $\left.1^{\prime \prime}\right) /$ planet gear $p(-76: 29)$

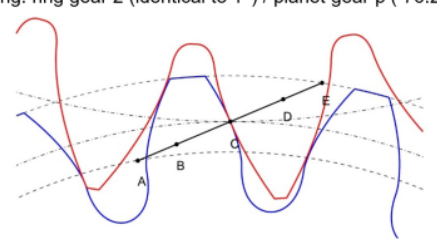

Gearing: sun gear 1 / planet gear $p$ (20:29)

Fig. 11. Picture of gear meshes for low-loss-gears for sub-transmission I.

Fig. 11 shows the exemplary gears for such an application. It can be seen that the internal gear has special teeth as the requirement for pitch point $C$ in the middle of the line of contact lead to such a form of the gears. The safety factor for such teeth is sufficiently high and mainly influenced by the radius of curvature in the tooth root.

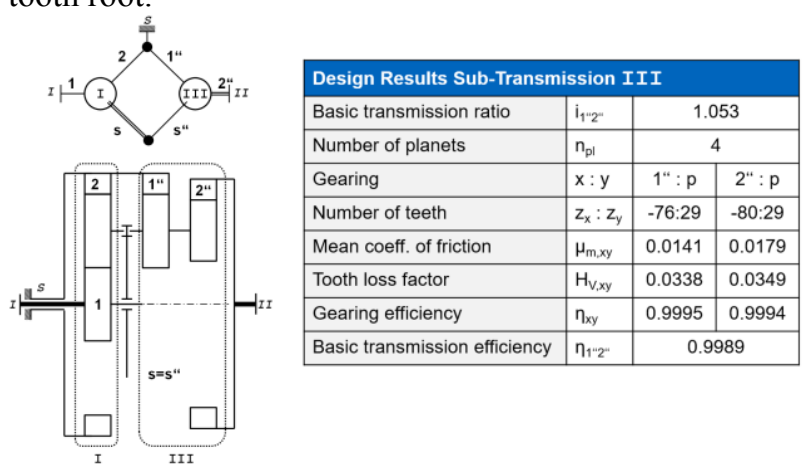

Fig. 12. Low-loss-gears for sub-transmission III.

Fig. 12 illustrates the result for sub-transmission III (plus-transmission). The program calculates the values for $\eta$ with the given parameters of the gear mesh. These values are different for every configuration and not valid for all applications. In both contacts, the sliding factor $\mathrm{HV}$ is low. Consequently, the gearing efficiency values are high and the basic transmission efficiency for such type of transmission is about 0.999 that means the losses are about $1 \%$ If you compare this value with the subtransmission I with 0,993 , it can be seen that this type is characterized by a high efficiency as the value of losses of type I is seven times higher than of type III. 

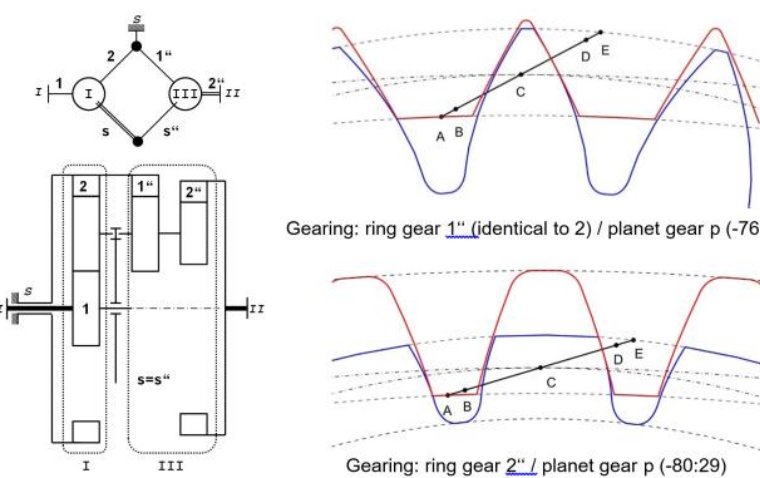

Gearing: ring gear 1 “" (identical to 2$) /$ planet gear $p(-76: 29)$

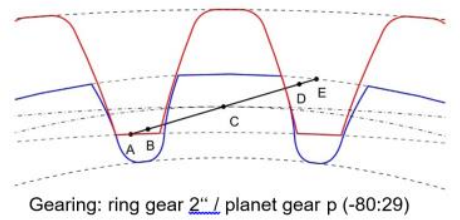

Fig. 13. Picture of gear meshes for low-loss-gears for sub-transmission III.

Fig. 13 shows the exemplary gears for this solution. The base circle for the common planet leads to one involute for the planet, Both have the same number of teeth but different tip diameters. Especially the mesh 80:29 shows an unusual size of the tooth but the requirements for low-loss-gears are fulfilled. The pitch point $\mathrm{C}$ is in the middle of the line of contact, the same like in the gear mesh of $-76: 29$. The main difference is the pressure angle $\alpha_{w}$. For the first case $-80: 29$, the pressure angle $\alpha_{w}$ is smaller than the angle from the standard range, that means $\alpha_{\mathrm{w}}$ is smaller than $20^{\circ}$. For the gear mesh of $-76: 29$, the pressure angle is high, in this example $\alpha_{w}$ is higher than $30^{\circ}$. These values are very different, but with unusual profile values, they can be realized. The size of these teeth are both untypical, which can be seen in Fig. 13, but nevertheless the safety factors for bending und pressure-contact acc. to ISO 6336 can be calculated and fulfill the requirements as for a usual tooth geometry. In Fig. 13, it can be seen that the tip-diameter of the second planet is small and the tip width is high. This will be used for further investigations (refer to Fig. 21 and Fig. 22).

Efficiency Factor for Standard Tooth Geometry [1] [4]:

$$
\begin{gathered}
\eta_{12}=0.9975 \cdot 0.9981=0.9956 \\
\eta_{1 \mathrm{~S}}=\left(\mathrm{i}_{12} / \eta_{12}-1\right) /\left(\mathrm{i}_{12}-1\right)= \\
(0.95 / 0.9956-1) /(0.95-1)=0.916 \sim 0.92
\end{gathered}
$$

Efficiency Factor for low-loss-Tooth Geometry:

$$
\begin{gathered}
\eta_{12 \text { opt }}=0.9995 \cdot 0.9994=0.9989 \\
\eta_{1 \mathrm{~S}}=\left(\mathrm{i}_{12} / \eta_{12}-1\right) /\left(\mathrm{i}_{12}-1\right)= \\
(0.95 / 0.9989-1) /(0.95-1)=0.979 \sim 0,98
\end{gathered}
$$

Fig. 14. Efficiency for plus-transmission III in the Wolfrom transmission with standard and low-loss-gears.

Fig. 14 show the effect in efficiency for the subtransmission III (the plus-transmission with the ratio close to $i=1$ ). If the efficiency of this plus-transmission with normal gears and the one for low-loss-gears are compared the difference can be seen clearly. For the normal gears, the efficiency $\eta_{\text {IS }}$ is about 0.92 and for the low-loss-gear about 0.98 . Considering the total losses of the Wolfrom transmission with the two sub- transmissions, the efficiency can be improved from about 0.9 to 0.97 . These values are calculated without any bearing, sealing and splash losses. Nevertheless, the effects of low-loss-gears are relevant but for this example (wind turbines) not sufficient and satisfying the customers.

\section{Wolfrom transmission without carrier}

Fig. 15 illustrates a first schema of a Wolfrom transmission without any radial bearings in the carrier.

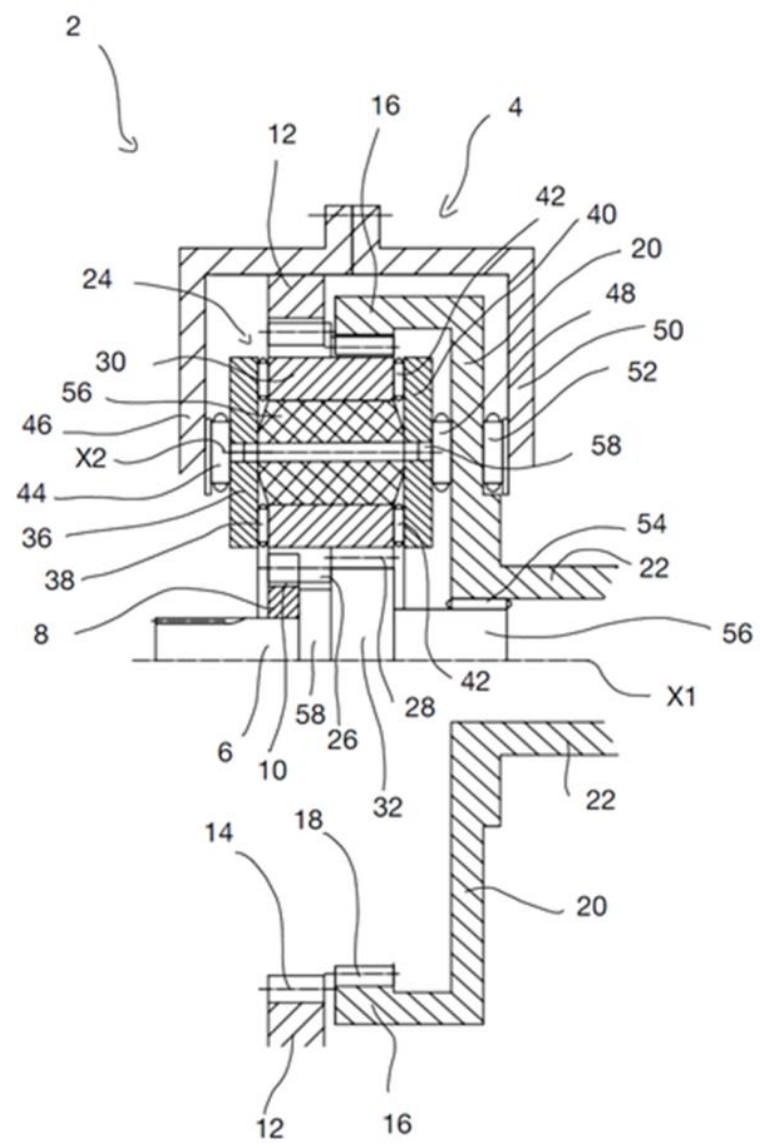

Fig. 15. Schema of Wolfrom transmission out of patent application [9].

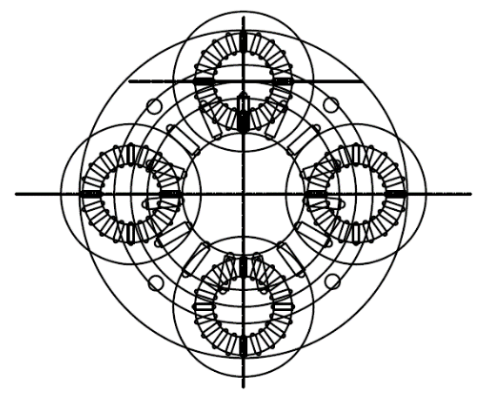

Fig. 16. View to the 4 planets of the new Wolfrom transmission [9].

Though, is there no carrier needed? The two plates 36 and 40 are the rest of the carrier. They are used to transfer the axial forces from the planet to the housing 
directly. The two plates are connected with four screws, which can be seen in Fig. 16. They connect the two plates and transfer the axial forces $F_{a x 1}$ and $F_{a x 2}$ from one plate to the other. If they are not elastic (that means total stiff), no axial forces must be transferred to the housing across the axial bearings 44,48 and 52 . In reality, the plates are elastic and will be deformed by the forces. That means that the weak plates have an elastic deformation, which can be calculated with FEM and leads to forces to the axial bearings 44,48 and 52 . These forces can be transferred to the housing.

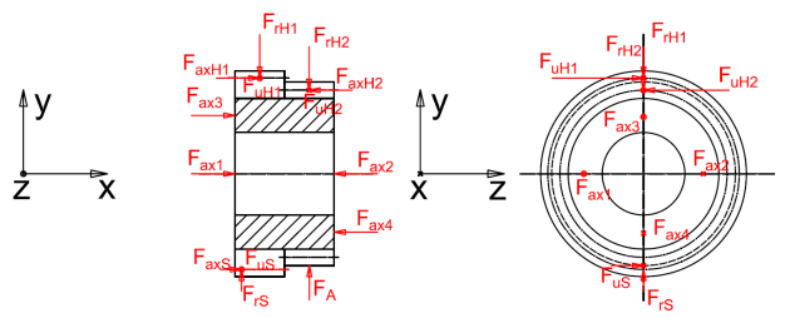

Fig. 17. Forces at the planet 30.

Fig. 17 illustrates the planet with one involute geometry and two different tip diameters for the two gear meshes with the internal gears $\mathrm{z}=-76$ and $\mathrm{z}=-80$. All forces present in the design arise in the contact of the two internal gears and the sun and the supporting ring 32 (fig. 15). This ring contacts the planet in the pitch diameter of the contact sun-planet. That means that no sliding in this contact occurs, only the radial forces from the gear meshes with the two internal gears will be applied and can be calculated from the other radial forces from the planets (see Fig. 17). That means that the planet doesn't need a radial bearing. The twisting moment from the radial forces, which will be applied to the planet, can be supported by axial forces $F_{a x 3}$ and $\mathrm{F}_{\mathrm{ax} 4}$, which will be supported by the two plates as well. The ring 32, which is aligned to the sun and the input shaft, has the same function than the supporting sun gear ("Stützsonne") in Fig. 3 but with nearly no losses as there is no sliding in the contact between ring 32 and the tip diameter of the planet. That means that the efficiency of this Wolfrom transmission is supposed to be higher than the design shown in Fig. 3.

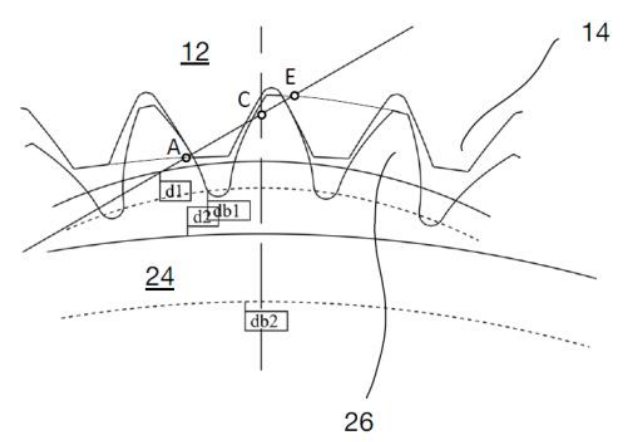

Fig. 18. Gear mesh -76:29.

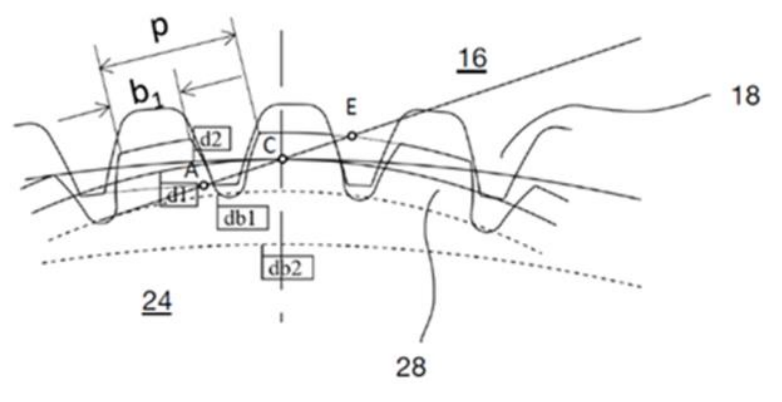

Fig. 19. Gear mesh -80:29.

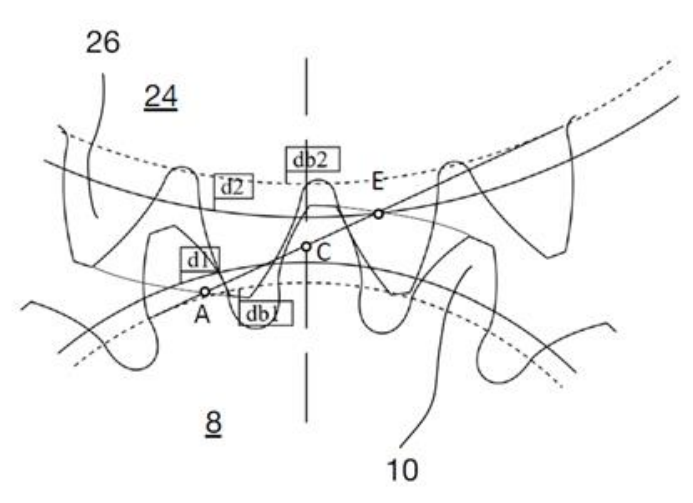

Fig. 20. Gear mesh sun-planet 20:29.

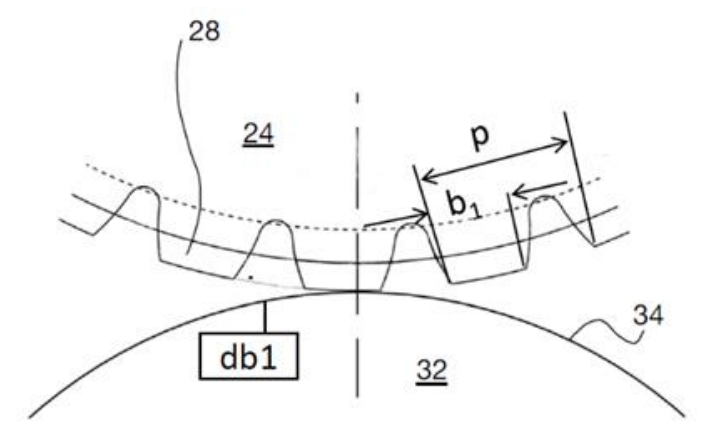

Fig. 21. Contact tip diameter planet to ring 32, applied with $\mathrm{F}_{\mathrm{A}}$.

Fig. 18 to 20 show the gear meshes between the two internal gears and the planets and the gear mesh sunplanet (according to Fig.11 and Fig. 13) but with helical gears as the contact of the ring 32 and the tip diameter should not be interrupted.

Fig. 22 illustrates the contact line between the ring and the tip diameter of the planet. With an overlap-ratio $\varepsilon_{\beta}$ of $>1$, a constant length of the line of contact is realized. For different position of the sun (or input shaft), the lines of contact are shown. 


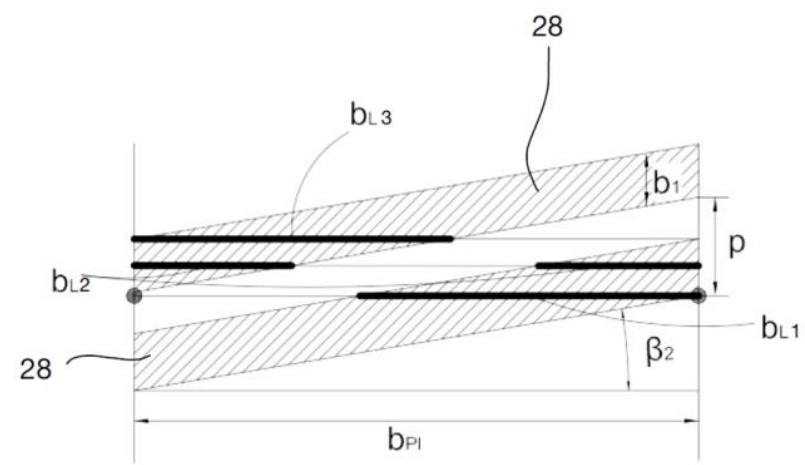

Fig. 22. Lines of contact of tip diameter to ring 32 .

\section{Conclusion}

The new Wolfrom transmission is characterized by three main differences compared to existing Wolfrom transmissions:

1. The use of low-loss-gears leads to a much higher efficiency in the gear meshes. The losses in the gear meshes are significantly lower.

2. The resulting radial forces at the planets are not supported by bearings. No radial bearings are in the planets and in the carrier. So no carrier to transmit any radial forces is necessary.

3. The twisting moments for the axis direction $Y$ and $\mathrm{Z}$ (see Fig. 17) lead to axial forces in the axial bearings. They are also shown in Fig. 17. The losses are lower than for radial bearings, though the overall efficiency would be higher than for existing variants and the gaps can be measured and nearly neglected. This results in a stable and constant efficiency.

\section{References}

1. Müller, H.W. Die Umlaufgetriebe (Springer Verlag 2. Auflage 1998, ISBN 3-540-63227-1)

2. Arnaudov, K. Einfaches Verfahren zur Ermittlung des Übersetzungsverhältnisses zusammengesetzter Planetengetriebe. VDI-Bericht 1230,VDI-Verlag GmbH, Düsseldorf (1996)

3. Arnaudov, K., Kariavanov,D.P. Planetary gear trains (CRC Press 2019, ISBN 978-1-138-31185-5)

4. Niemann, G.; Winter, H. Maschinenelemente Band II (Springer-Verlag, 1996)

5. DE $4224850 \mathrm{~A} 1,1984$

6. DE $202009018547 \mathrm{U1}, 2009$

7. DE $19845182 \mathrm{~A} 1,2000$

8. Wimmer, A. Lastverluste von Stirnradverzahnungen - Konstruktive Einflüsse, Wirkungsgradmaximierung, Tribologie (FZG-Dissertation. 2006)

9. DE $102020111001.4,2020$ 